necessary to prepare pure orthonitrophenylpropiolic acid; if orthonitrocinnamic acid (No. 2 above) be treated with bromine, then with alcoholic potash, and lastly with grape-sugar, without separating the various products indigo-blue is produced. Orthonitrocinnamic acid may be prepared, without difficulty, from oil of bitter almonds. Artificial indigo may be directly printed on cloth by mixing orthonitrophenylpropiolic acid-or orthonitro. phenyloxyacrylic acid described below-with soda and grape- or milk-sugar, and after proper thickening, soaking the cloth in the mixture, and heating: or the material may be simply soaked in orthonitrophenyloxyacrylic acid and heated.

Orthonitrophenyloxyacrylic acid is prepared by the action of alcoholic potash on an alcoholic solution of orthonitrophenylchlorolactic acid (itself prepared by the action of chlorine on orthonitrocinnamic acid), in accordance with the equation-

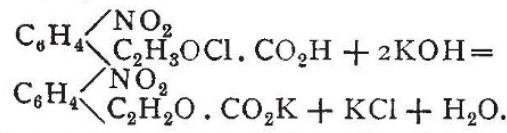

By boiling an aqueous solution of orthonitrocinnamic acid dibromide (No. 3 above) with sodium carbonate, indigo blue separates out.

M. M. P. M.

\section{MICROSCOPIC STRUCTURE OF MALLEABLE METALS}

$$
T^{H E}
$$

$\mathrm{HE}$ following observations on the minute structure of metals, which have been hammered into thin leaves, are instructive. Notwithstanding the great opacity of metals, it is quite possible to procure, by chemical means, metallic leaves sufficiently thin to examine beneath the microscope by transmitted light. Silver leaf, for instance, when mounted upon a glass slip and immersed for a short time in a solution of potassium cyanide, perchloride of iron, or iron-alum, becomes reduced in thickness to any required extent. The structure of silver leaf may also be conveniently examined by converting it into a transparent salt by the action upon it of chlorine, iodine, or bromine. Similar suitable means may also be found for rendering more or less transparent most of the other metals which can be obtained in leaf.

An examination of such metallic sections will show two principal types of structure, one being essentially granular, and the other fibrous.

The granular metals, of which tin may be taken as an example, present the appearance of exceedingly minute grains, each one being perfectly isolated from its neighbours by still smaller interspaces. The cohesion of such leaves is very small.

The fibrous metals, on the other hand, such as silver and gold, have a very marked structure. Silver, especially, has the appearance of a mass of fine, elongated fibres, which are matted and interlaced in a manner which very much resembles hair. In gold this fibrous structure, although present, is far less mar'sed. The influence of extreme pressure upon gold and silver seems to be, therefore, to develop a definite internal structure. Gold and silver in fact appear to behave in some respects like plastic bodies. When forced to spread out in the direction of least resistance their molecules do not move uniformly, but neighbouring molecules, having different velocities, glide over one another, causing a pronounced arrangement of particles in straight lines.

This development of a fibrous structure, by means of pressure, in a homogeneous substance like silver, is an interesting lesson in experimental geology, which may serve to illustrate the probable origin of the fibrous structure of the comparatively homogeneous limestones of the Pyrenees, Scotland, and the Tyrol.

$$
\text { J. VINCENT ELSDEN }
$$

\section{ISLAND LIFE 1}

II.

T $\mathrm{N}$ the second half of his volume $\mathrm{Mr}$. Wallace proceeds to apply to the elucidation of the history of the characteristic assemblages of plants and animals in islands, the principles laid down with so much explicitness in the first half. He points out that for the purposes of the naturalist a fundamental difference exists between islands that have once formed part of continents and those which have not. Continental islands are those which, by geological revolutions at more or less remote periods, have been severed from the continental masses in their neighbourhood. They are recognisably portions of the continental ridges of the earth's surface. This relation is usually made strikingly apparent by the chart of soundings between them and the nearest mainland (Fig. 2). Further, in geological structure they resemble parts of the continents, like which they contain both old and new formations, with or without volcanic accumulations. In some cases the evidence of recent severance from the adjacent continent is abundant. In others it is less distinct; for example, where the islands are separated from the nearest land by a depression of a thousand fathoms or more, and where their fauna, though abundant, is of a fragmentary nature, almost all the species being distinct, many of them forming distinct and peculiar genera or families, while many of the characteristic continental orders or families are entirely absent, and in their place come animals to which the nearest allies are to be found only in remote parts of the world. Oceanic islands, on the other hand, exhibit no geological connection with any continental area, but owe their birth either to upheaval of the ocean floor or to the piling up of lavas and tuffs round submarine vents of eruption. Their geological structure is of the simplest kind. As Mr. Darwin long ago showed, they consist of volcanic rocks or of coral reefs, or of volcanic and coralline formations combined. Ancient formations, so characteristic of continental islands, are wholly wanting. These islands lie far removed from a continent, and rise from water of profound depth. Their fauna is in curious keeping with this isolation, for it contains no indigenous land-mammals or amphibians, but abounds in birds and insects, and usually possesses some reptiles. These animals or their ancestors must have reached the islands by crossing the ocean.

Mr. Wallace first attacks the problems presented by the Oceanic Islands (Fig. I). He describes the characters of the flora and fauna of the Azores, Bermuda, the Galapagos, St. Helena, and the Sandwich Islands, and endeavours in each case to show how the resemblances and differences between them and the plants and animals of the continents may be accounted for. The contrast offered by two groups of islands on either side of the American continent - the Bermudas and Galapagosbrings vividly before the mind the nature of the difficulties with which the author grapples, and the methods by which be seeks to solve them. In the case of the Bermuda group a series of coral islets having a total area of no more than fifty square miles rises from the very deepest depression in the Atlantic basin in $32^{\circ} \mathrm{N}$. lat. at a distance of 700 miles from North Carolina. The chief elements in the fauna of these islands are birds and landshells. Upwards of I 80 species of birds have been observed, more than half of which belong to wading and swimming orders, while eighty-five are land-birds, of which twenty species are frequent visitors. Only ten species live as permanent residents on the island, and these are all common North American birds. No bird, and indeed no vertebrate animal, save a species of lizard, is peculiar to Bermuda. The feathered population of the islands is dez "Island Life ; or, the Phenomena and Catuses of Insular Faunas and Floras," \&c. By Alfred Russel Wallace. (London: Macmillan and Co., x880.) Continued from p. 359 
rived from the North American continent, whence every year, especially during the autumnal storms, numbers of birds are blown out to sea. Most of these no doubt perish, but some succeed in reaching Bermuda. Hence from this constant introduction of fresh individuals there has been no development even of any distinct variety in the avian fauna. The land-shells include twenty species, of which at least four, or about a fourth of the whole, are peculiar. The proportion of peculiar land-shells among the Azores is about a half of the whole number of resident species. It is obvious that these organisms have comparatively feeble and uncertain means of transport as compared with birds. They may be carried only at widely separated and irregular intervals, enclosed in drift-wood from some other island or continent. Hence the conditions for their gradual change under the new circumstances of their insular home are exceptionally favourable. The flora of Bermuda contains a majority of tropical and West Indian plants, and includes a number of species identical with

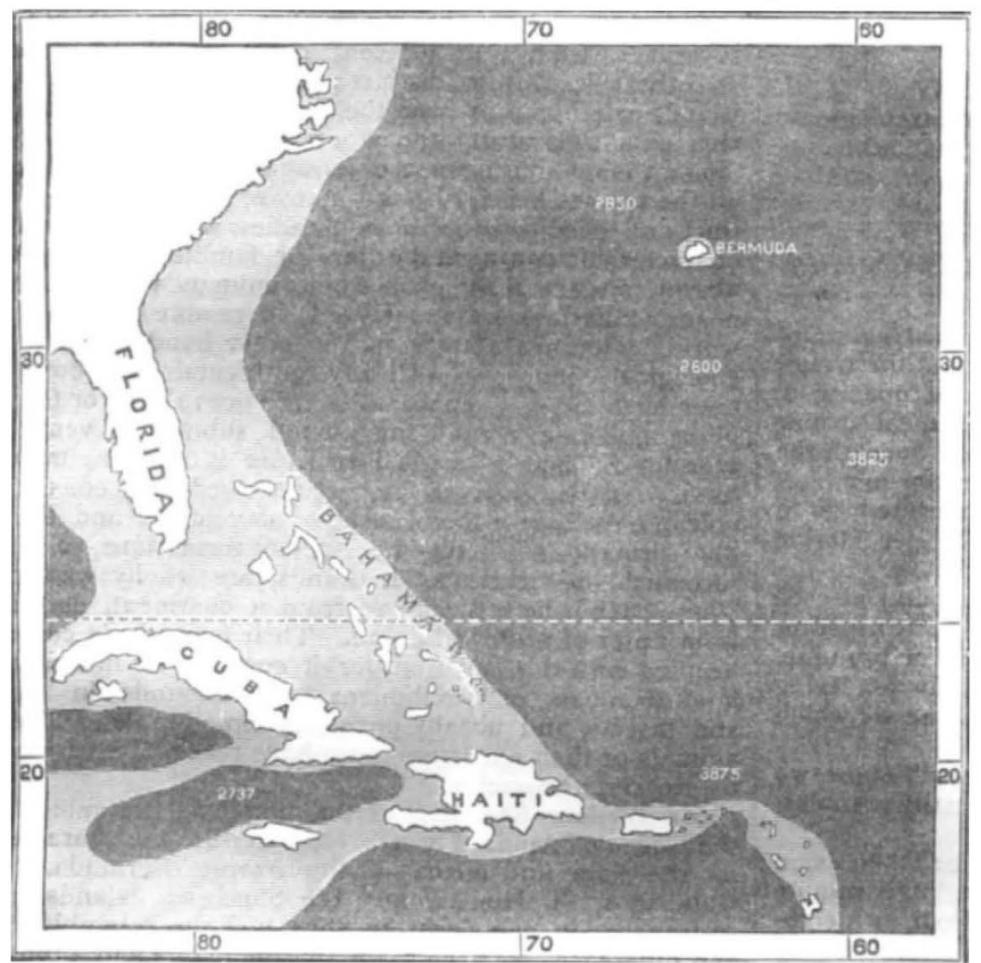
Fig. I. - Map of Bermuda and the American Coast. The darker tint indicates sea more than roo,
fathoms deep, the lighter shows sea less than rooo fathoms. The figures mark the depth in fathoms.

those in the Southern States of the American Union. The origin of this vegetation is thus easily traced, first, to the operation of marine currents, whereby plants of the West Indian Islands have been actually observed to be washed ashore on Bermuda and to germinate there; next, of cyclones by which fine seeds transported in the higher parts of the atmosphere may doubtless be easily carried from the American continent; and thirdly, of birds, which among their feathers and in the mud adhering to their feet are known to transport living seeds to enormous distances.

The Galapagos, though less distant from the west side of the American continent than the Bermudas are from the east side, rise nevertheless out of a profoundly deep ocean. The whole group of seventeen islands ranges over an area of 300 miles in length by 200 in breadth, being of volcanic origin, and still containing in the western islands numerous active volcanoes. Between the fauna of the Galapagos however and that of the nearest part of South America a remarkable difference obtains. As usual, no indigenous mammalia or amphibia occur in these islands; but a few species of reptiles abound-landtortoises, lizards, and snakes, that find their nearest allies on the American continent, whence doubtless their ancestors at some remote period were derived. Cut of a total of fifty-seven species of birds no fewer than thirtyeight are peculiar. In particular the land-birds number thirty-one species, which are all, with but one exception, confined to the Galapagos, and more than half of them are so peculiar as to be ranked in distinct genera, though all are undoubtedly allied to birds inhabiting Tropica. America: Mr. Wallace points out that every gradation can be traced, from perfect identity with continental species to marked generic divergence, and that "this diversity bears a distinct relation to the probabilities of and facilities for migration to the islands." A species which is widely diffused and essentially migratory will,

by frequent arrival of fresh individuals from the parent stock and intercrossing, continue unchanged, while others, in proportion to the rarity of their reintroduction, will be subject to all the variation which change of habitat and prolonged isolation may incluce. The flora of these islands includes I74 peculiar flowering-plants, and $158 \mathrm{com}$ mon to other regions. Among the latter occur forms found both in North and South America, with some that range into the West Indies. Sir Joseph Hooker has observed that the peculiar plants of the Galapagos are allied to forms now found in temperate America, or in the high Andes, while the nonpeculiar species are such as live in tropical latitudes near the sea-level. These facts in zoological anc botanical distribution the author seeks to explain by the meteorological conditions and geological history of the region. The Galapagos Islands lie in a tract of almost perpetual calms. The storms that annually transport a fresh immigration of birds and seeds to the Bermudas are there unknown; consequently the fauna and flora present a far greater contrast to those of the continent than is the case of Bermuda. The presence of West Indian species is regarded as pointing to the former submergence of the Isthmus of Panama and the consequent drifting of those forms from the north-east, perhaps by a deflected branch of the Gulf Stream. Again, the affinity of a portion of the Galapagos flora to plants of northern or sub-alpine types is looked upon as an indication of that ancient southward migration of northern forms consequent upon the extension of the snow and ice of the Glacial Period.

As examples of Continental Islands the author describes the British Isles, Borneo, Java, Japan, Formosa, and the Madagascar group. The difference between the plants and animals of continental islands and those of the neighbouring continents varies extensively, one main effective element in the case being the length of time during which insular relations have been established. Taking Britain as perhaps the most typical illustration of a large and recently separated continental island (Fig. 2), Mr. Wallace points out how many are the proofs of comparatively recent subsidence, which he regards as the cause of the severance of Britain from the continent. Undoubtedly subsidence was one, probably the prircipal, 
operation whereby the British Islands were isolated. We must not forget however that denudation also played its part. The excavation of the Strait of Dover, for example, may have been in large measure effected by streams diverging from the watershed and partly by the littoral erosion of the waves as they advanced upon the slowly foundering land. The recent date of the separation of Britain is shown by the identity of the fauna as a whole with that of France and Germany. But as compared with the continent, the British Isles are remarkably poor in species. In Germany, for example, there are nearly ninety species of land mammals; even Scandinavia possesses about sixty; but Britain can boast only forty--a number which in Ireland is reduced to twenty-two. Still more remarkable is the contrast presented by the reptiles and amphibia; for while Belgium possesses twenty-two species, Britain can show no more than thirteen, and Ireland has only four. This progressive diminution of the fauna westward is even illustrated by animals possessing the power of flight, though, as might be supposed, it is in these cases less strongly marked. The twelve bats of Britain are reduced to seven in Ireland, the 130 land-birds to about IIO. In Britain 1425 species of flowering plants and ferns are known, but in Ireland only 970 , or two-thirds of the British flora. The reason assigned by $\mathrm{Mr}$. Wallace for this poverty of species is the extensive submergence of the British Islands during the later stages of the Glacial Period. He believes that the interval between the subsequent elevation and the final separation of Britain from the continent cannot have been of long duration. It was indeed sufficiently prolonged to allow of the migration westwards of a considerable part of the Post-glacial fatna and flora, but the insular condition was established before more than a part had succeeded in reaching Britain, where both the soil and climate would have been eminently favourable for the reception of the rest. The time that has elapsed since our area ceased to be continental has been long enough for the production of a few peculiar varieties. No distinct species or variety of mammal, reptile, or amphibian has arisen. But we possess three peculiar birds-the coal-tit, long-tailed tit, and grouse-fifteen peculiar species of fresh-water fishes, sixty-nine lepidopterous insects, seventy-two beetles, four caddis-flies, and four terrestrial and fluviatile shells believed to be peculiar. In the flora the chief contrasts are exhibited by the mosses and hepaticæ, of which respectively seventeen and nine forms appear to be peculiar. This mode of considering the British fauna and flora brings out in clear relief the relations between them and those of the continent, and their bearings upon the question of the origin of peculiar forms. Not only do the British Islands as a whole contain species or varieties that do not appear on the mainland of Europe, but some of our outlying islands, such as the Shetland Isles, the Isle of Man, and Lundy Island, possess each its local forms that are not met with on the main island.

As "anomalous islands" the author classes together Celebes and New Zealand, the former because it belongs to no one of the six zoological regions of the globe, and cannot be certainly affirmed to have been united to a continent, the latter because in some respects it may be regarded as an oceanic, in others as a continental island. Celebes is supposed by Mr. Wallace to be probably a fragment of Miocene Asia, preserving down to the present time a few remnants of its Tertiary fauna, together with an intermixture of more modern types that have been introduced by ordinary means of dispersal. Three interesting chapters are devoted to New Zealand, and in these is discussed the important question of the origin of the European element in the floras of the temperate southern latitudes.

Enough has been said here to show the nature and value of this new contribution to scientific literature. Even where Mr. Wallace's conclusions may be disputed, they are always of the most suggestive kind. His volume, as he acknowledges, is the development and application of a theory; but it is not written in the spirit of a mere partisan. Its facts are of course marshalled in such form as most effectively to sustain the theory; yet with a transparent directness and honesty of purpose that runs through the whole book, and gives it one of its great charms. The writer does not consciously shut his eyes to any of the difficulties of his case. Candidly admitting them, he presents such explanation as seems to him to offer the most likely pathway to their ultimate solution.

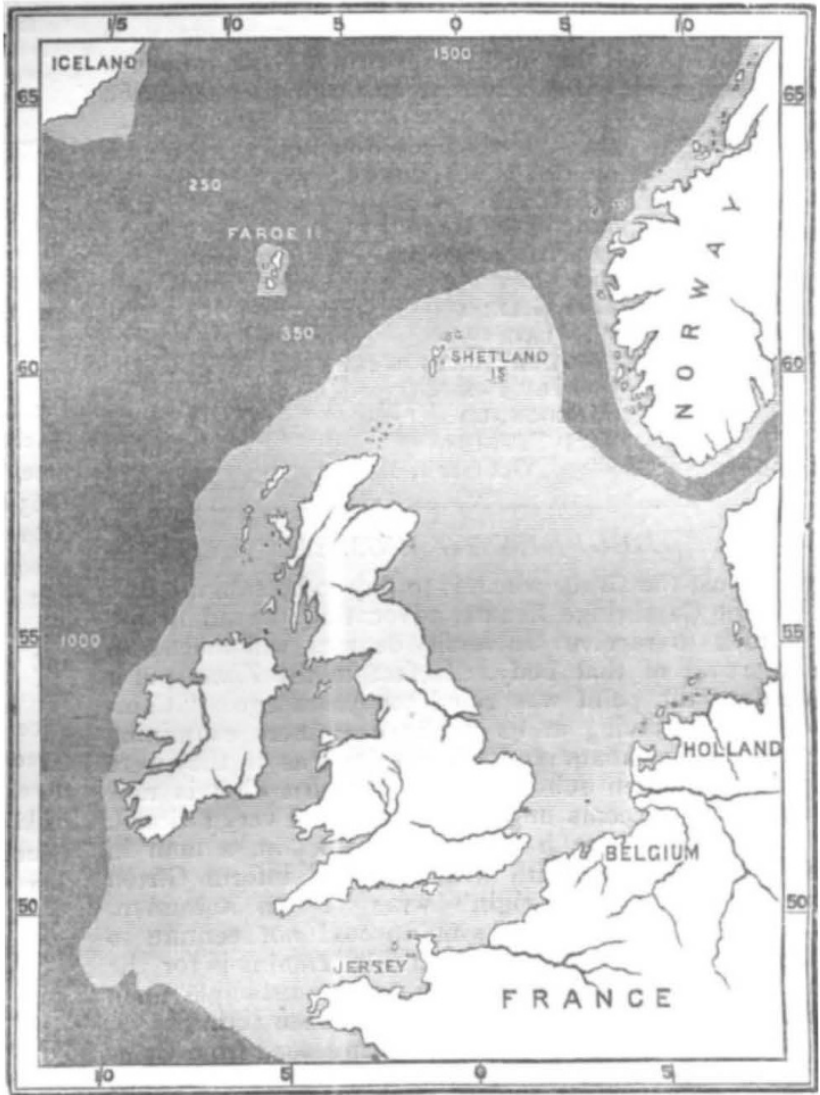

IG. 2.-Map of the shallow bank connecting the British Isles with the Continent. The dark tint marks sea of more than, the paler tint shows sea of less than, rooo fathoms n depth. The figures show the depth in fathoms. The narrow channel between Norway and Denmark is 2580 feet deep.

He deserves the thanks alike of geologists and of biologists for a treatise, the appearance of which marks another epoch in the history of the doctrine of Evolution.

ARCH. TEIKIE

\section{HONOUR TO MR. DARWIN}

THE following address to Mr. Darwin, from New Zealand, speaks for itself :-

\section{To Charles Darwin, Esq.}

SIR,-We, the members of the Council of the Otago Institute, beg to offer you our congratulations on this, the 